\title{
The Fuzzy Control Automation Architecture of Parallel Action for the Intelligent Smart Grid Networks
}

\author{
STANISLAV BOVCHALIUK \\ The Department of Automation and the Computer Integrated Technologies \\ Kharkiv Petro Vasilenko National Technical University of Agriculture \\ 19, Rizdviana Str., Kharkiv, 61052 \\ UKRAINE \\ bovchaliuk@ukr.net \\ SERGII TYMCHUK \\ The Department of Automation and the Computer Integrated Technologies \\ Kharkiv Petro Vasilenko National Technical University of Agriculture \\ 19, Rizdviana Str., Kharkiv, 61052 \\ UKRAINE \\ stym@i.ua \\ SERGII SHENDRYK \\ The Department of Computer Science \\ Sumy State University \\ 2, Rymskogo-Korsakova Str., Sumy, 40007 \\ UKRAINE \\ s.shendryk@cs.sumdu.edu.ua \\ VIRA SHENDRYK \\ The Department of Computer Science \\ Sumy State University \\ 2, Rymskogo-Korsakova Str., Sumy, 40007 \\ UKRAINE \\ v.shendryk@cs.sumdu.edu.ua
}

\begin{abstract}
Some technology introduction problems of Smart Grid in the electric networks of Ukraine are considered in the article. It is offered to apply the automats of parallel action in control system by a power supply. It is offered to make alteration in the structure of parallel action classical automat for the decision of problem vagueness detains. The general strategy is set for the construction of parallel action automats with fuzzy logic.
\end{abstract}

Key-Words: - SMART GRID, PLD-controller, parallel action automat, technology of parallel logical management, fuzzy logic.

Received: March 12, 2019. Revised: January 3, 2020. Accepted: February 11, 2020. Published: February 25, 2020.

\section{Introduction}

The modern state of electric networks in Ukraine needs modernization. In addition, the permanent increasing on the electric system takes place. It is conditioned by the consumers amount increasing and specific consumption of energy by consumers. An additional call for power engineering specialists is swift development of the so-called "green" energy - wind power-stations, sunny stations sources, etc $[1,2,3]$. Energy sources characteristics are:
- mainly small generating power;

- its instability (day's, weather, etc.);

- distribution of electric networks.

These features do not allow integrating such sources to the existent electric networks. They require introduction of considerable changes to organization and maintenance of Ukrainian power economy.

The power trend progress is clearly defined in energy well - developed countries. Its basic theses 
are nonbreaking and co-ordination actions for providing three constituents:

- energy supply (trouble proof electric energy supply of corresponding quality);

- energy availability (energy safety and availability of price on electric power);

- to energy acceptability (minimum influence on an environment) [4].

Thus, Ukraine has a unique chance to modernize power economy to the level technically and the economically developed countries. Also, there is a necessity to move in direction of construction the intellectual new generation power system. It will allow bringing the power services grant to conformity with the standards of progressive world countries.

\section{Problem Formulation}

Intellectualization conception of electro energy has an aim to build fully integrated, self-regulated and self-reproduced system. Such system has a network topology and includes all generating sources, bus and distributive networks, all types of electric energy consumers. This system should follow by a single network of automated devices in real time [1, 4]. This conception got the universally recognized and generally accepted term - Smart Grid. So, Europe determination is European Technology Platform Smart Grids: (intellectual networks) are electric networks that satisfy the future requirements, in relation to energy efficiency and economy of grid functioning. It takes place due to the coordinated functioning and by means of modern bilateral communications between the elements of electric networks, electric stations, heatsink sources and consumers $[5,6]$.

World leaders in development and introduction of Smart Grid conception [4] is:

- the USA - The Energy Independence and Security Act of 2007;

- countries of EU - Smart Grid Technology Roadmap Report Development;

- South Korea - Smart Country Strategy Development.

In these countries, it is set the pilot schemes of different intellectual content grade and different readiness rates. Operating data accumulate gradually, complication and volume of innovative power hubs increase.

Movement of Ukraine in direction to the electric systems intellectualization on the base of Smart Grid conception was announced by the head of HEK
"Ukrenergo" Vsevolod Kovalchuk. It is planned the pilot scheme realization of Smart Grid - Vehicle - to - Grid (V2G) technology cooperative work of electric vehicle and electric system. Besides it is planned a research of possibility to use next groups of technologies:

- Demand Response;

- Virtual Power Plant.

In the authors' opinion, one of perspective realization ways of Smart Grid elements is information technology application of parallel logical management on the base of safe PLDcontroller of parallel action. This technology was developed for the management of continuous cyclic action objects. It was practically realized for the management of critical application (responsible, reliable, faultless) objects. However, processes carry, mainly, indefinite character in electric networks. In the consequence of its direct application of the indicated technology in energy cannot give considerable advantages in comparing the classic methods and technologies of successive action. However, if connect the elements of fuzzy logic with information technology of parallel logical management, it can give an effective instrument for the Smart Grid construction.

The main goal of this research is form conception of logical management function realization in an unclear form on the base of parallel action automat. Form the way to build elements of intellectual power circuit within the framework of Smart Grid conception on the base of fuzzy logic automat of parallel action (FLAPA).

\section{Problem Solution}

There are at least two reasons for mathematical vehicle application of fuzzy logic:

- presence of vagueness input quantity;

- natural parallelism of logical induction procedure.

We shall consider these reasons.

Presence of vagueness input quantity. Problems of making decisions in energy find in the conditions of incompleteness and vagueness of external information. It results in the receipt of inexact results. In accordance to [7] a vagueness takes place, if an universal set consists more than of one point. For example, a vagueness arises up in the process of parameters measuring that determine technological processes in energy. Such vagueness's can have different nature:

- inaccuracy (or error) of measuring devices, 
- presence of different values forming of the plural measuring;

- second-rate measuring, for example through dispersed after a parameter or after territory, etc.

In such cases, the classic systems of logical management use determination (for example by the method of statistical average procession). Thus, the part of data is lost.

Natural parallelism of logical induction procedure. Such natural parallelism allows to integrate the elements of fuzzy logic realization in the structure of classic parallel action automats. It will allow extending their functionality and ways of application.

The first FLAPA prototype is a device for machine management a machine for casting under pressure [8]. The simplified structure of this device is shown on Fig. 1. The blocks on the indicated structure of discriminators $\mathrm{D}_{1}$ and $\mathrm{D}_{2}$ execute phasing of analog signal inputs. They lead signal inputs (Input 1, Input 2) for three levels - more (>), norm $(n)$, less $(<)$. Logical processing unit (LPU) sets the algorithm of technological function process. Regulators $R_{1}-R_{3}$ form the equipment management signals (Output 1 - Output 3 ). They execute function of defuzification.

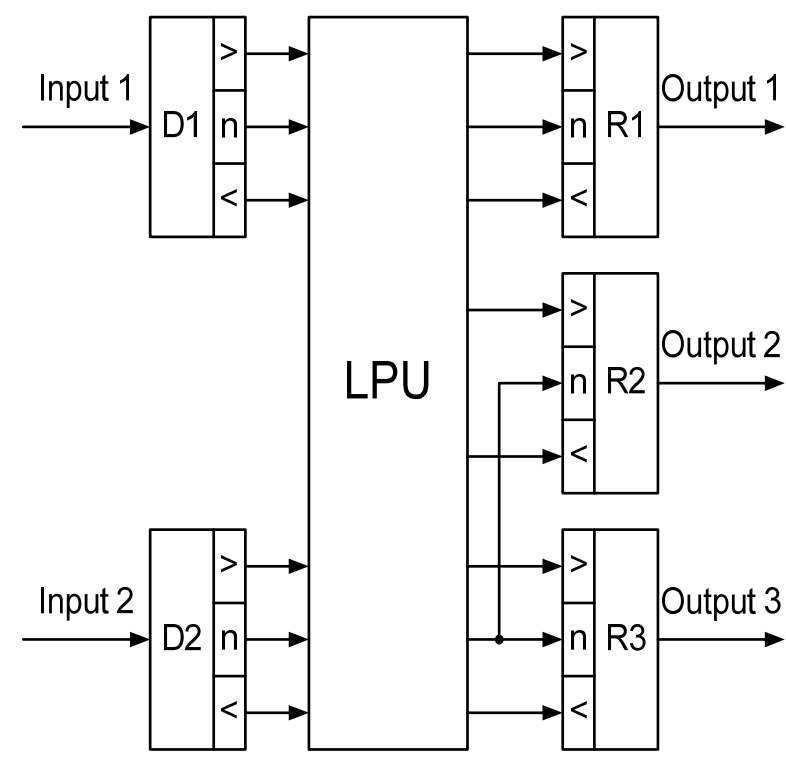

Fig.1 Simplified structure of FLAPA prototype.

The actually shown structure presents the hard logic of parallel action automat. An automat did not envisage programming and was realized on an element base that time.

We shall consider the input data possible variants for the synthesis of FLAPA structure. In general view, they can be three types:

- the analogue;
- digital binary;

- digital fuzificated.

The analogical data types can be realized on the automat outputs.

In a general view, FLAPA can be presented as follows (Fig. 2), where: $a_{1} \ldots a_{k}-\kappa$ digital binary inputs; $g_{1} \ldots g_{p}-p$ analog inputs; $c_{1} \ldots c_{m}-m$ digital binary outputs; $f_{x l} \ldots f_{x n}$ are data fuzificated outputs; $f_{y l} \ldots f_{y l}$ are data fuzificated outputs. Thus, data fuzificated inputs and outputs actually present an ordinary binary code.

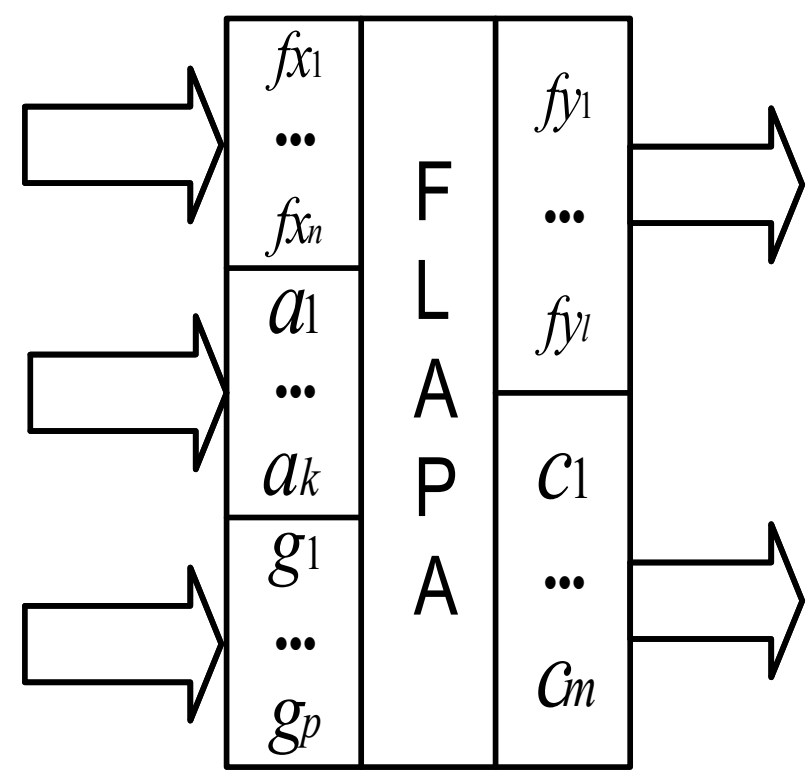

Fig.2 The generalized FLAPA structure

If consider ordinary digital and digital fuzificated data inputs, then it is possible to reach the next conclusion: binary data is possible to present as unclear, but with a value $\mu$, only 0 and 1 . For the unclear data form $\mu$ can possess any value from 0 to 1.

The example of such data membership functions is shown on Fig. 3. Digital data after procedure of fuzification present the ordinary binary code of certain bit. A bit depends on necessary exactness of phazification. Thus, the synthesis of FLAPA structure both types of data input can be presented as a set of binary numbers $k+z n$, where $z$ is a bit of data fuzification.

Analog data on the automat input transform in digital form before obligatory. That is analog data as a result of analog-digital transformation will be presented by a parallel digital binary code. Thus, data inputs for FLAPA of all mentioned types actually present the parallel binary code of certain bit. The same output data of all types can be presented by an analogical code.

At the FLAPA synthesis important questions show up: 
- what amount of input quantity in an unclear form can treat by an automat?

- how many output commands of management can be formed?

Theoretical an amount of logical managing parallel action automat inputs-outputs (LAPA) is unlimited, thus an amount of FLAPA inputs is also unlimited. It is possible to assert from experience of industrial prototypes creation of parallel action inspectors, that the amount of inputs-outputs, limited to complication of technical realization and procedure of managing cyclogram realization.
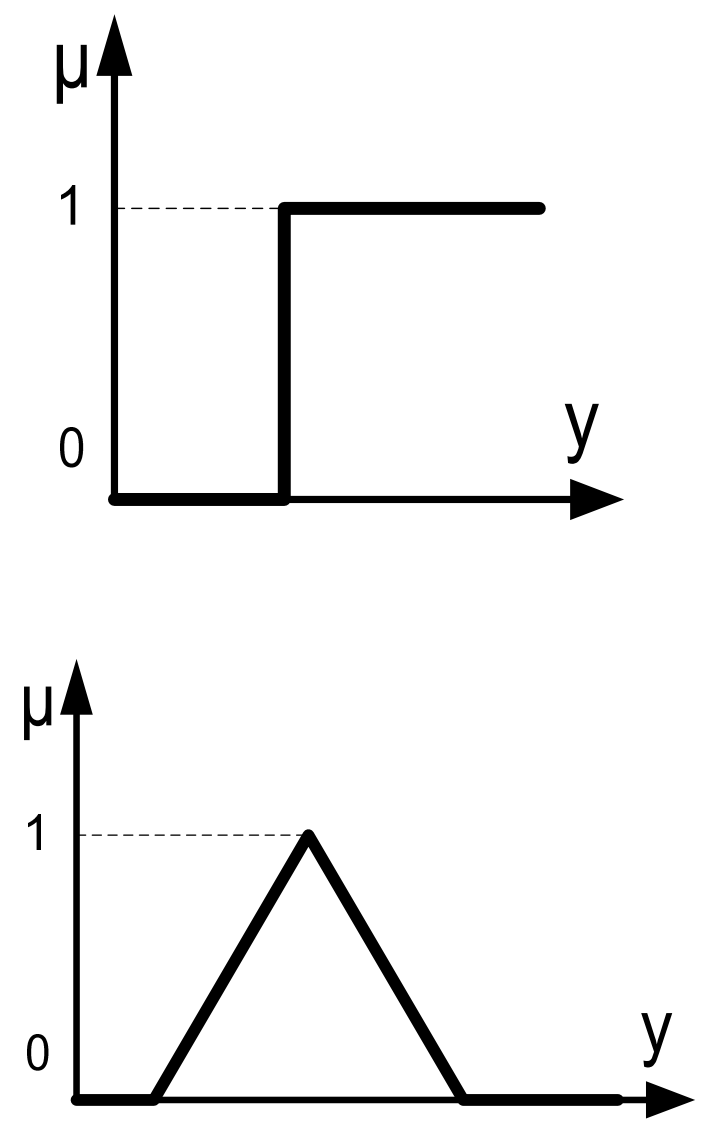

Fig.3 General view of function $\mu$ for data in a binary and unclear form

At plenty of input quantities, it is suggested to apply FLAPA cascading. It will allow breaking up intricate problems to simpler. Realization of such approach is shown on Fig. 4. Therefore, every FLAPA works only with two unclear sizes. The result of two sizes treatment, in an unclear form, is passed to next FLAPA, where co-operates with the third unclear size. A process recurs farther. Analog and binary data are not examined in this instance, as can treat on any of the stages. $f x_{n}$

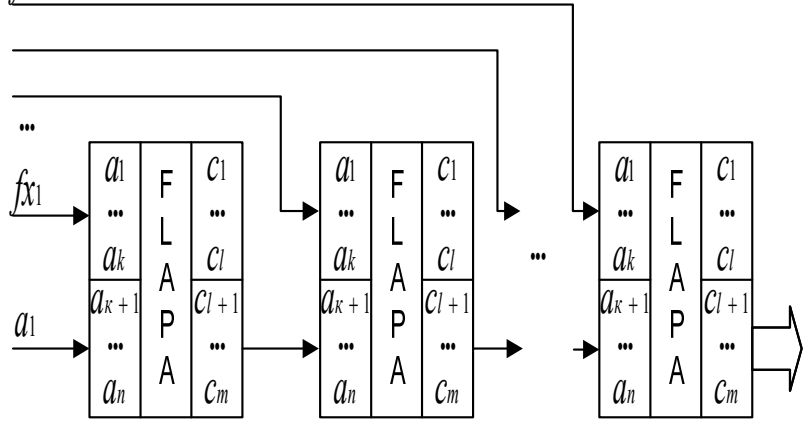

Fig.4 FLAPA cascading.

It is possible to do the next conclusion: classic structure of LAPA (Fig. 5), can be based for the synthesis of FLAPA structure.

LAPA consists of follow elements: display unit $\mathrm{DU}$; schemes of comparing unit - $\mathrm{CU}$; logic operation selection block - LOSB; logic control unit - LCU; address counter - AC; output register - OR; and also blocks of states memory, commands, transitions and forbidden combinations - SMU, CMU, JMU, UCMU.

Proceeding from the tasks that belong to FLAPA, it is suggested to enter following changes to its structure:

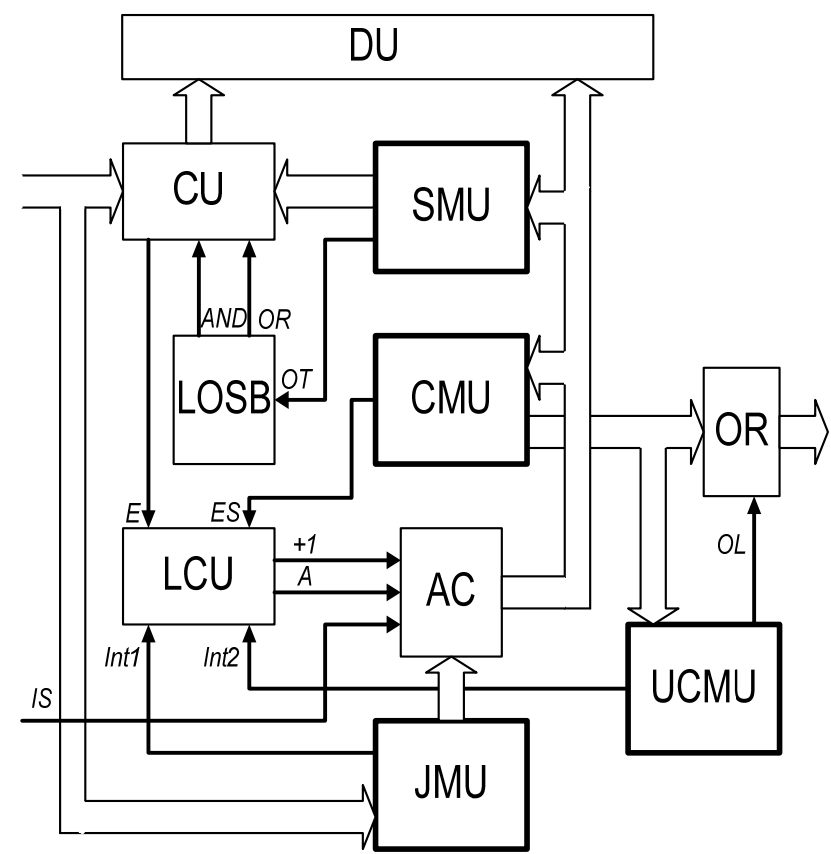

Fig.5 LAPA structure

- whereas the questions of management safety are not examined and not grounded, it is possible to eliminate the blocks of БПЗК and SR. They provided non-extradition of the forbidden combinations of initial 
commands managements that is why they are unnecessary.

- to eliminate DU, as information delivery about current status of input data is not actual.

- other blocks remain in the FLAPA structure, though change its functional value.

Proposal generalized FLAPA structure is shown on Fig. 6.

FLAPA work differs from LAPA, by following features:

- JMU loses the basic functionality from address of subroutine to computation. It, both with CMU, intended for storage of forming table unclear inferencing;

- SMU contains only the fragments of successive implementation of commands, if there is a necessity in them. If such determined sequence is absent, then SMU is eliminated from a structure;

$\mathrm{AU}$ executes the same functions, that $\mathrm{AC}$ in LAPA. Now its basic function is forming of unclear inferencing with JMU, but not successive working off the subprogram lines with SMU.

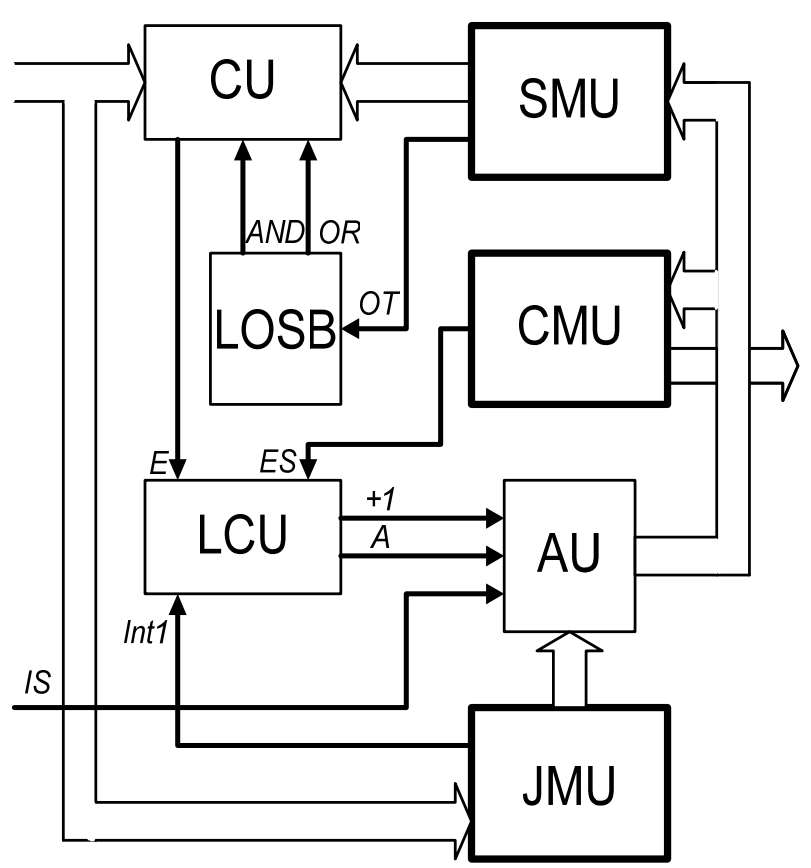

Fig.6 FLAPA structure

\section{Conclusion}

The research showed that fuzzy logic was an effective instrument for a power equipment management. It allows realizing the automats of parallel action for a management such equipment for one time of discrete automat time. It is also well proven that the base LAPA structure can be taken for basis at the synthesis of the generalized FLAPA structure. It allows passing to the practical synthesis of automats structures, its HDL- models and physical realization. Thus, elements of information technology of parallel logical management can be taken for basis for the construction of intellectual kernel modern clever Smart Grid energetics.

\section{References:}

[1] O. Shulyma, V. Shendryk, I. Baranova, A. Marchenko, The features of the smart microgrid as the object of information modeling, Communications in Computer and Information Science, Vol. 465, 2014, pp.12-23.

[2] V. Shendryk, O. Shulyma, Y. Parfenenko, The topicality and the peculiarities of the renewable energy sources integration into the Ukrainian power grids and the heating system, Renewable and Alternative Energy: Concepts, Methodologies, Tools, and Applications. IGI Global Publisher, Chapter 45, pp. 1317-1349, 2016.

[3] O. Shulyma, V. Shendryk, Y. Parfenenko, S. Shendryk, The model for decision support on design of the hybrid renewable energy system, Proceedings of the 2017 IEEE 9th International Conference on Intelligent Data Acquisition and Advanced Computing Systems: Technology and Applications, IDAACS 2017, pp. 47-50.

[4] B. Stognii, O. Kyrylenko, O. Prahovnyk, S. Denysiuk, The evolution of intelligent electrical networks and their prospects in Ukraine, Technical Electrodynamics, Vol. 5, 2012, pp. 52-67.

[5] Smart Grid - European Technology Platform for Electricity Networks of the Future. European Commission, 2005. [Electronic resource] - Mode of access: http://www.smartgrids.eu/.

[6] European Technology Platform- Smart Grids. April 2011: Strategic Deployment document for European Commission, 2014. [Electronic resource] - Mode of access: http://www.smartgrids.eu/.

[7] A. Kandel, W. Byatt Fuzzy sets, fuzzy algebra, and fuzzy statistics IEEE proc. 1619 - 1639, 1978.

[8] A. s. 1026946 USSR, MKI3 B 22 D 17/32. Ustroistvo upravlenyja mashinoy dlia litija pod davlenijem / Kostritsa V., Furman I. (USSR). №3425477/22-02 ; zaiavl. 20.01.82 ; opubl. 07.07.83, Bul. № 25 . 